\title{
Genetic variance of Derzsy's disease strains isolated in Poland
}

\author{
Grzegorz Woźniakowski*, Wojciech Kozdruń and Elżbieta Samorek-Salamonowicz \\ Department of Poultry Viral Diseases, National Veterinary Research Institute, Al Partyzantów 57, 24-100 Puławy, Poland \\ *Correspondence to: Grzegorz Woźniakowski, Email: grzegorz.wozniakowski@piwet.pulawy.pl, Tel: +48 818893032 , \\ Fax: +48818862595
}

Received 17 August 2009, Revised 29 October 2009, Accepted 03 November 2009, Published online 30 November 2009

J Mol Genet Med (2009), 3(2), 210-216

(C) Copyright The Authors: This is an open access article, published under the terms of the Creative Commons Attribution Non-Commercial License (http://creativecommons.org/licenses/by-nc/2.0/uk/). This license permits noncommercial use, distribution and reproduction of the article, provided the original work is appropriately acknowledged with correct citation details.

\begin{abstract}
The aim of this study was the assessment of the genetic variance of Derzy's disease (GPV) strains isolated from cases occurring in Poland. The nucleotide and predicted aminoacid sequences of VP2 and VP3 surface proteins of the Polish GPV strains were compared with other strains previously isolated in Hungary, France, Germany, China and Taiwan. The observed genetic variance of the aminoacid sequence within the group of Polish strains was low and reached $5 \%$ of the overall analysed sequence. Considerable differences in aminoacid sequence were found in the case of Polish field GPV strains and Muscovy duck parvovirus strain MDPV FM which was also analysed in this study. The conducted investigations confirmed the presupposition that Polish GPV strains and strains previously isolated in Hungary and France share a common origin.
\end{abstract}

KEYWORDS: Derzsy's disease, goose parvovirus, Muscovy duck parvovirus, genetic variance, phylogenetic analysis

\section{INTRODUCTION}

Derzsy's disease (DD) is an infectious viral disease of waterfowl which causes serious economic loss in industrial production of geese and Muscovy ducks. The etiological agent of the disease is Derzsy's disease virus (DDV) or goose parvovirus (GPV), which belongs to Dependovirus genus and Parvovirdae family. Among Muscovy ducks (Carina moschata) similar clinical sympthoms to Derzsy's disease are caused by Muscovy duck parvovirus (MDPV). The capsids of GPV and MDPV are non-enveloped, 20-22 $\mathrm{nm}$ in diameter and assembled from 32 capsomers. The GPV genome is represented by a $5106 \mathrm{nt}$ long single-stranded DNA and that of MDPV by a $5132 \mathrm{nt}$ long single-stranded DNA. The terminal ends of the DNA strand are flanked by inverted terminal repeats (ITRs) (Le Gall-Recule et al, 1994; Gough et al, 1998). Within the GPV and MDPV genomes two main open reading frames (ORFs) can be identified - the primer ORF encoding regulatory proteins involved in virus replication and the latter ORF encoding structural proteins of the capsid. The structural proteins VP1, VP2 and VP3 are encoded by the same DNA sequence characterized as 'basket structure' with common 3 ' end for all structural proteins. The molecular weight of the VP2 and VP3 proteins are approximately 65 and 60 $\mathrm{kDa}$, respectively, and assemble the outer structure of GPV and MDPV capsids (Cotmore et al, 2006). The genetic variance of the waterfowl parvoviruses are mainly observed in the nucleotide sequence of the surface proteins interacting with the immuno-competent cells of the host (Chu et al, 2000). Such genetic variance is considerably lower within the sequence of regulatory proteins involved in replication and protein expression of these viruses. Analysis of the whole sequence of GPV and MDPV conducted by Zàdori et al revealed that the DNA sequence of VP2 and VP3 regions include conserved and variable domains (Zàdori et al, 1995). The point mutations in the sequences encoding structural proteins could be the main cause of changes in immunogenic properties of the viruses that could have influence on the efficiency of vaccination against GPV and MDPV (Tàtar-Kis et al, 2004). These 
differences were used for the determination of genetic variance and possible evolution of Derzsy's disease virus strains isolated in Poland during the past seven years (2000-2007), and one Muscovy duck parvovirus strain FM (CEVA - Phylaxia, Hungary).

\section{MATERIALS AND METHODS}

\section{Viruses}

Ten field strains of goose parvovirus isolated from field cases of DD were used. The numbers of the strains used were the following: 14/01, 14/02, 9/03, 24/03, 33/03, 54/03, 8/07, 16/07, G/07 (Kozdruń et al, 2008). The vaccine strain PIW-82 was taken from Dervac vaccine (NVRI). The MFP strain came from Palmivax vaccine (Merial - France). The MDPV FM was obtained from CEVA Laboratories, Hungary.

\section{Cell cultures}

Goose embryo fibroblasts (GEFs) cultures were prepared from 14-days old embryos according to standard procedure (Gough et al, 1998). Uninfected GEF cells were used as negative control. Cells were cultured in Eagle's medium supplemented with $10 \%$ (v/v) calf serum and $1 \%(\mathrm{v} / \mathrm{v})$ mixture of antibiotics: $1 \mathrm{U} / \mathrm{ml}$ penicillin , $1 \mu \mathrm{g} / \mathrm{ml}$ of streptomycin, $0.25 \mu \mathrm{g} / \mathrm{ml}$ of amphotericin B and Fungizone ${ }^{\circledR}$ Antimycotic in $0.85 \%(\mathrm{w} / \mathrm{v})$ saline (Antibiotic-Antimycotic-Gibco); the Eagle's medium with antibiotics but lacking calf serum was used as the maintaining medium. The GEF cells were inoculated in suspension at the density of $0.8 \times 10^{6}$ cells per $\mathrm{ml}$ with the chosen strains of GPV and MDPV. After inoculations the cells were incubated at $37^{\circ} \mathrm{C}$ for 7 days under $5 \%$ (v/v) $\mathrm{CO}_{2}$. Each day the cultured cells were examined under an optical microscope for appearance of any cytopathic effects. The occurrence of cytophatic effect in the infected monolayer culture cells in the form of tiny rounded cells refracting light were noted between 5 and 7 day post infection. In the infected cell cultures the syncytias were formed while the continuity of the cells monolayer was disrupted. Such effects are characteristics, induced of Derzsy's disease virus. Viral particles were released from cells by three freeze-thaw cycles. The resultant suspension was used for further inoculation of the next GEFs passage. This step was repeated 3 times, and $\mathrm{TCID}_{50}$ titers for each viral strain were determined. The titers ranged from $10^{4.8}$ to $10^{5.2}$ TCID $_{50}$ in $0.2 \mathrm{ml}$. The third passage was used as virus pool for further investigations.

\section{DNA extraction}

Cells were taken at third passage and viral particles were released from cells by three freeze-thaw cycles. The suspension was centrifuged at 1400rpm (rotor 11469, MPV 350R centrifuge) for $5 \mathrm{~min}$. Total cellular DNA was extracted from the pelleted virus particles according to kit manufacturer's instructions (QIAamp DNA Mini Kit, Qiagen).

\section{Primers and amplification conditions}

The primers complementary to VP2 and VP3 encoding regions were designed using 'Primer3' online software on the basis of complete genomes of $B$ strain of GPV accession number U25749 and FM strain of MDPV accession number U22967 from the NCBI Genebank. The primer sequences were as follows:

\section{VP2F: 5' GAGCCATTTGGCCTAGTA 3'}

\section{VP2R: 5' CATATCCACCAGTTTCATTAGGTG 3'}

\section{VP3F: 5' GTGCCGATGGAGTGGGTAAT 3'}

\section{VP3R: 5' GCGCCAGGAAGTGCTTTAT 3'}

The primers were tested for homology using the Genebank BLAST database (http://blast.ncbi.nlm.nih.gov/blast.cgi). The amplified products produced by these primers for the VP2 and VP3 regions were 1763bp and 1604bp, respectively.

The amplification reactions were carried out in $25 \mu$ l volume using HotStart Taq DNA polymerase (Qiagen). Each reaction contained $2.5 \mu \mathrm{l} 10$-fold PCR buffer with $1.5 \mathrm{mM}$ $\mathrm{MgCl}_{2}, 0.2 \mu \mathrm{M}$ dNTPs, 2.5U HotStar Taq Polymerase, $5 \mu 1$ $1 \mathrm{M}$ betaine solution (Sigma), primers at $0.4 \mu \mathrm{M}$ each and $2 \mu \mathrm{l}$ of DNA template $(\sim 0.5 \mu \mathrm{g} / \mu \mathrm{l})$. Amplification was carried out under the following conditions: VP2 and VP3 regions; initial denaturation $95^{\circ} \mathrm{C} / 5 \mathrm{~min}$, then 35 cycles of $94^{\circ} \mathrm{C}$ for $1 \mathrm{~min} ., 60.2^{\circ} \mathrm{C}$ for $1 \mathrm{~min}, 72^{\circ} \mathrm{C}$ for $1 \mathrm{~min}$, and final elongation step of $72^{\circ} \mathrm{C}$ for $10 \mathrm{~min}$. The PIW-82 vaccine strain extracted from the Dervac vaccine (NVRI) was used as the positive control, and DNA extracted from the noninfected cell cultures of goose embryo fibroblasts (GEF) was used as negative control.

The sensitivity of both amplification reactions was established under the standard conditions on the basis of eight 10 -fold dilutions $\left(10^{3}, 10^{2}, 10^{1}, 10^{0}, 10^{-1}, 10^{-2}, 10^{-4}, 10^{-5}\right)$ of DNA extracted from PIW-82 strain (NVRI), whose titer was determined at TCID $_{50}=10^{4}$ in $0.2 \mathrm{ml}$.

The amplified products were separated in $1.5 \%(\mathrm{w} / \mathrm{v})$ agarose gel at $120 \mathrm{~V}$ for $40 \mathrm{~min}$ and were visualized under UV (Vilber-Lourmat) after staining with ethidium bromide $(0.5 \mu \mathrm{g} / \mathrm{ml})$ for $15 \mathrm{~min}$. DNA GeneRuler ${ }^{\mathrm{TM}} 100 \mathrm{bp}$ DNA Ladder Plus (Fermentas) was used as molecular weight standard.

\section{Nucleotide sequencing}

The PCR products were purified from agarose gels using QIAquick Gel Extraction kit (Qiagen) according to the manufecturer's instructions. The products were sequenced using a modified dideoxynucleotide termination method by the Institute of Biochemistry and Biophysics in Warsaw on the ABI Prism 310 Instrument (Applied Biosystems). Each PCR product was sequenced twice. The obtained sequences from both of the primers were assembled into contigs using Bioedit software (Ver 7.0.4.1) and submitted to NCBI GeneBank (Table1). Phylogenetic analysis of the sequences and alignment of all sequences with NCBI Genebank was done in MEGA4 software (Ver 4026). Phylogenetic groups and trees were established on the basis of UPGMA method (Sneath and Sokal, 1973) with bootstrapping of each of the created branch. 
Table1. Accession numbers of submitted DNA sequences of VP2 and VP3 regions.

\begin{tabular}{|c|c|c|c|}
\hline $\begin{array}{c}\text { Accession } \\
\text { no. }\end{array}$ & Gene & Strain & Country \\
\hline GQ457900 & VP2 & $14 / 01$ & Poland \\
\hline GQ457901 & VP2 & $14 / 07$ & Poland \\
\hline GQ457902 & VP2 & $8 / 07$ & Poland \\
\hline GQ457903 & VP2 & G/07 & Poland \\
\hline GQ457904 & VP2 & MFP & France \\
\hline GQ457905 & VP2 & Piw-82 & Poland \\
\hline GQ457906 & VP2 & Palmivax & France \\
\hline GQ457907 & VP2 & $24 / 03$ & Poland \\
\hline GQ457908 & VP2 & $54 / 03$ & Poland \\
\hline GQ468402 & VP3 & MFP & France \\
\hline GQ468403 & VP3 & MDPV/FM & Hungary \\
\hline GQ468404 & VP3 & $9 / 03$ & Poland \\
\hline GQ468405 & VP3 & $14 / 01$ & Poland \\
\hline GQ468406 & VP3 & $14 / 07$ & Poland \\
\hline GQ468407 & VP3 & PIW-82 & Poland \\
\hline GQ468408 & VP3 & G/07 & Poland \\
\hline GQ468409 & VP3 & $16 / 07$ & Poland \\
\hline GQ468410 & VP3 & $54 / 03$ & Poland \\
\hline GQ468411 & VP3 & $24 / 03$ & Poland \\
\hline GQ468412 & VP3 & $8 / 07$ & Poland \\
\hline GQ468413 & VP3 & $14 / 02$ & Poland \\
\hline GQ468414 & VP3 & $33 / 03$ & Poland \\
\hline
\end{tabular}

\section{RESULTS}

All studied DNA samples of GPV strains, except MDPV FM, showed one characteristic amplicon of $\sim 1760 \mathrm{bp}$ representing amplified VP2. The VP3 region amplification from GPV strains as well as from MDPV FM strain presented a specific PCR product of $\sim 1600 \mathrm{bp}$. Sequenced contigs of VP2 and VP3 regions were compared with other accessible GPV and MDPV sequences available in NCBI Genebank. The Polish sequences of VP2 and VP3 regions were aligned with homologous sequences from Hungary, France, China, Taiwan, England and Germany. On the basis of the analysis of the nucleotide sequence encoding VP2 protein six different phylogenetic groups of GPV were distinguished (Figure 1). In the first group the strains originating from the territory of Hungary, GPV486 English strain and Chinese strains fell into the common lineage. The French strains fell into the second group while the third group was represented by strains from the territory of China as well as the Taiwanese TWL strain. The Polish strains constituted the fourth and sixth group (Figure 1). Three Polish strains, 24/03, 33/03 and PIW-82, presented the highly homologous VP2 sequence while six other strains, 54/03, MFP, 14/01, 8/07, 14/07 and G/07, established a separate group. Differences between the fourth and sixth group were confirmed by the analysis of the predicted amino acid sequence for the VP2 protein and were presented as a separate tree (Figure 2). The analysis of the amino acid sequence of VP2 protein of the Polish strains revealed the occurrence of two phylogenetic groups. The strains 33/03, 24/03 and PIW-82 were classified into the first group, while the strains $14 / 07$ and $\mathrm{G} / 07$ fell into the second group. The homology coefficient of the amino acid sequence of the Polish strains ranged from 83 to $100 \%$. The strains of Muscovy duck parvovirus (MDPV) originating from China, Taiwan and Hungary constituted a common fifth group (Figure 1). The topology of the particular branches of the VP2-based phylogenetic tree revealed that the studied strains possessed a common ancestor.

VP3 analysis produced nine groups. The analysis of VP3 encoding nucleotide sequences of the Polish and foreign strains from NCBI Genebank provided evidence of the relationship and divergence between GPV and MDPV strains, forming three phylogenetic groups (1,5 and 9) of these strains (Figure 3). In particular, the greatest diversity of the VP3 encoding region was found among strains isolated in China, which caused classification of these strains into three separate phylogenetic groups.

The first group consisted of the strains originating from Hungary, Polish vaccine strain PIW-82, Polish field strain 14/02 and GPV486 English vaccine strain. The second group was represented by FY, 99-1222, HEB, ZD, QTH and $\mathrm{ZZ}$ strain, whereas the third group was represented largely by Taiwanese strains (98-1218, TWL, 82-38, SP, 82-322). The strains originating from France and one Taiwanese strain 92-217 fell into the fourth group. Polish field strains of GPV: 14/01, 9/03, 24/03, 33/03, 54/03, $8 / 07,14 / 07,16 / 07$ and $\mathrm{G} / 07$ were classified into two different groups. Seven of them, 14/01, 9/03, 24/03, 33/03, $14 / 07,16 / 07$ and G/07, were classified into the fifth group but into two different branches even though their sequences were similar. Chinese strains DB-Q and DB-H formed Group 8. Two strains of identical sequence, 54/03 and $8 / 07$, were assigned to Group 9. The strains of Muscovy duck parvovirus FM, GD, TWK fell into a common group (Group 7), irrespective of their geographical origin. Moreover, on the basis of the analysis of the amino acid sequence of VP3 protein the GPV strains isolated in Poland, 24/03, 33/03 and 14/02, were classified into a common phylogenetic group (Figure 4). The high homology of the VP3 amino acid sequence was also found among strains 9/03, G/07, 16/07 and PIW-82. The most divergent was the sequence of the Polish MFP strain that showed $5 \%$ variation. The strains $14 / 01$ and $14 / 07$ as well as 54/03 and 8/07 were assigned into two different groups. The VP3 amino acid sequence of the MDPV FM differed by $16 \%$ as compared with other strains isolated in Poland. Despite this variation, overall, the data obtained in the present study suggest a common origin of the GPV and FM MDPV strains.

\section{DISCUSSION}

The methods used in the studies of phylogenetics and genetic diversity of Derzsy's disease virus include restriction analysis RFLP (Zàdori et al, 1994; Sirivan et al, 1998 ), and nucleotide sequence analysis of the consensus A region (2562-3054 bp) and B region (3172-3712 bp) of 


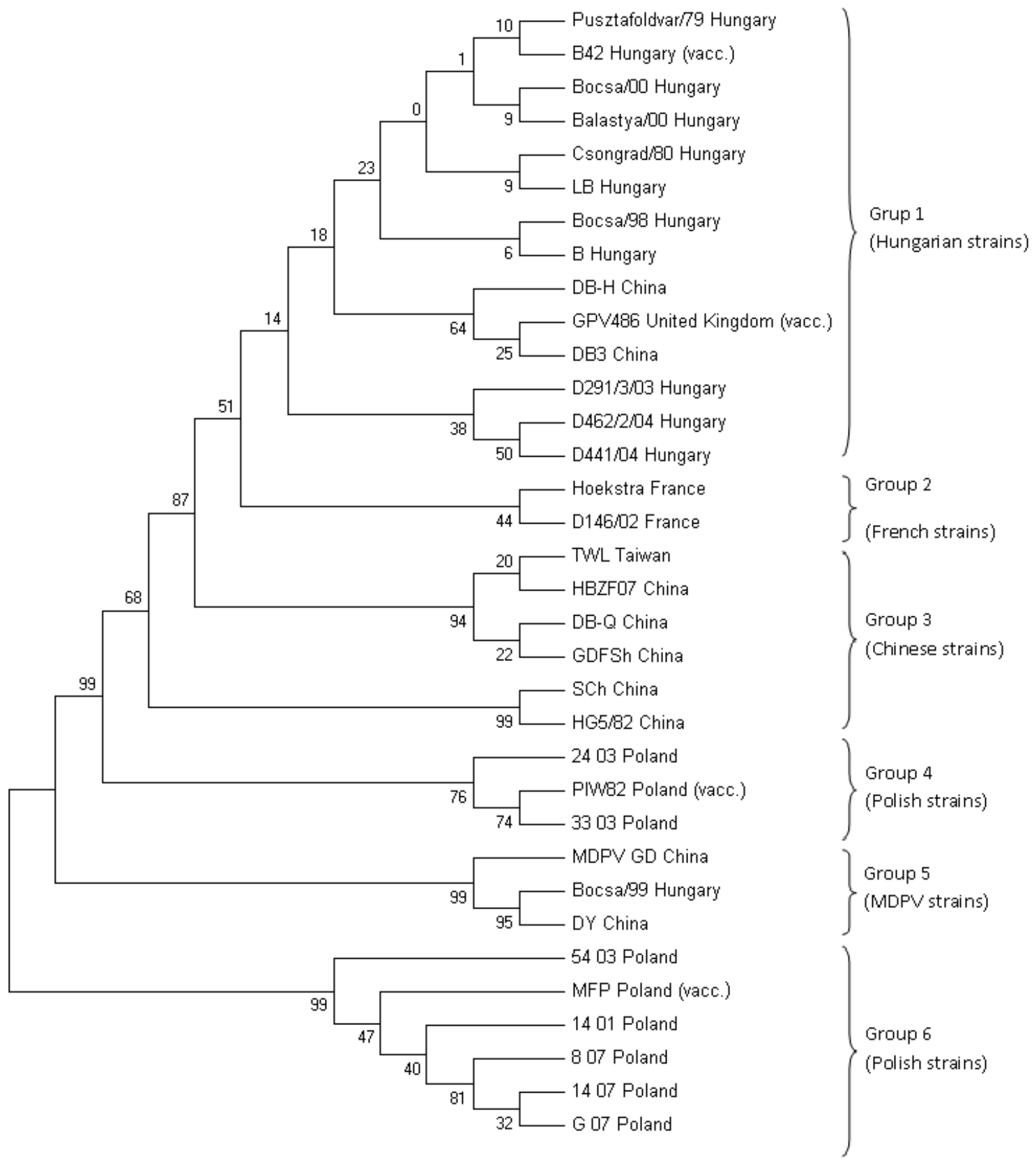

Figure 1. Phylogenetic tree of GPV and MDPV strains on the basis of VP2 encoding region (vacc.=vaccine strain)

Figure 2. Phylogenetic tree of the Polish strains of GPV on the basis of VP2 amino acid sequence. The values on the axis multiplied by $100 \%$ give the identity coefficient of strains.

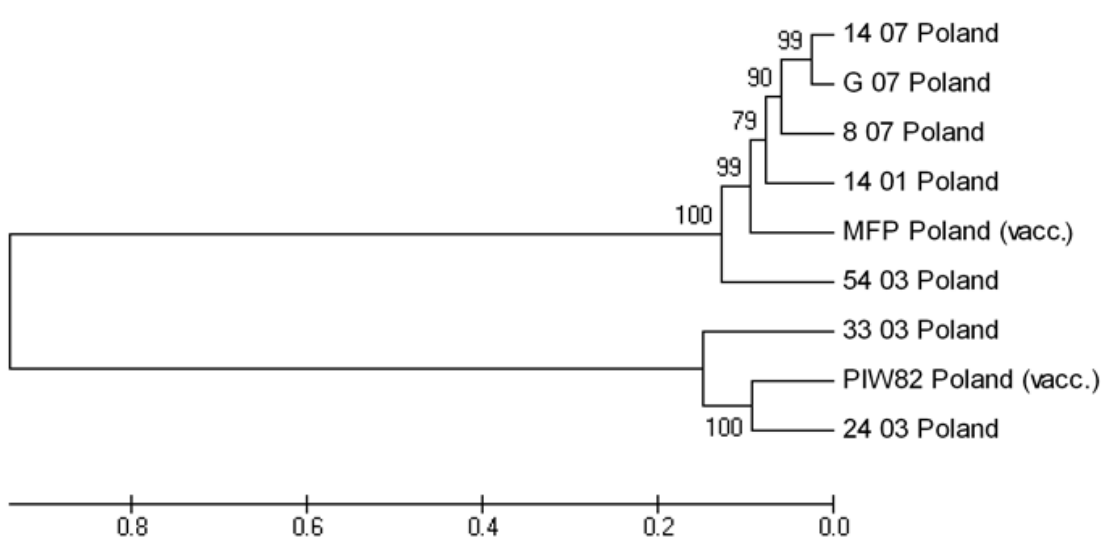



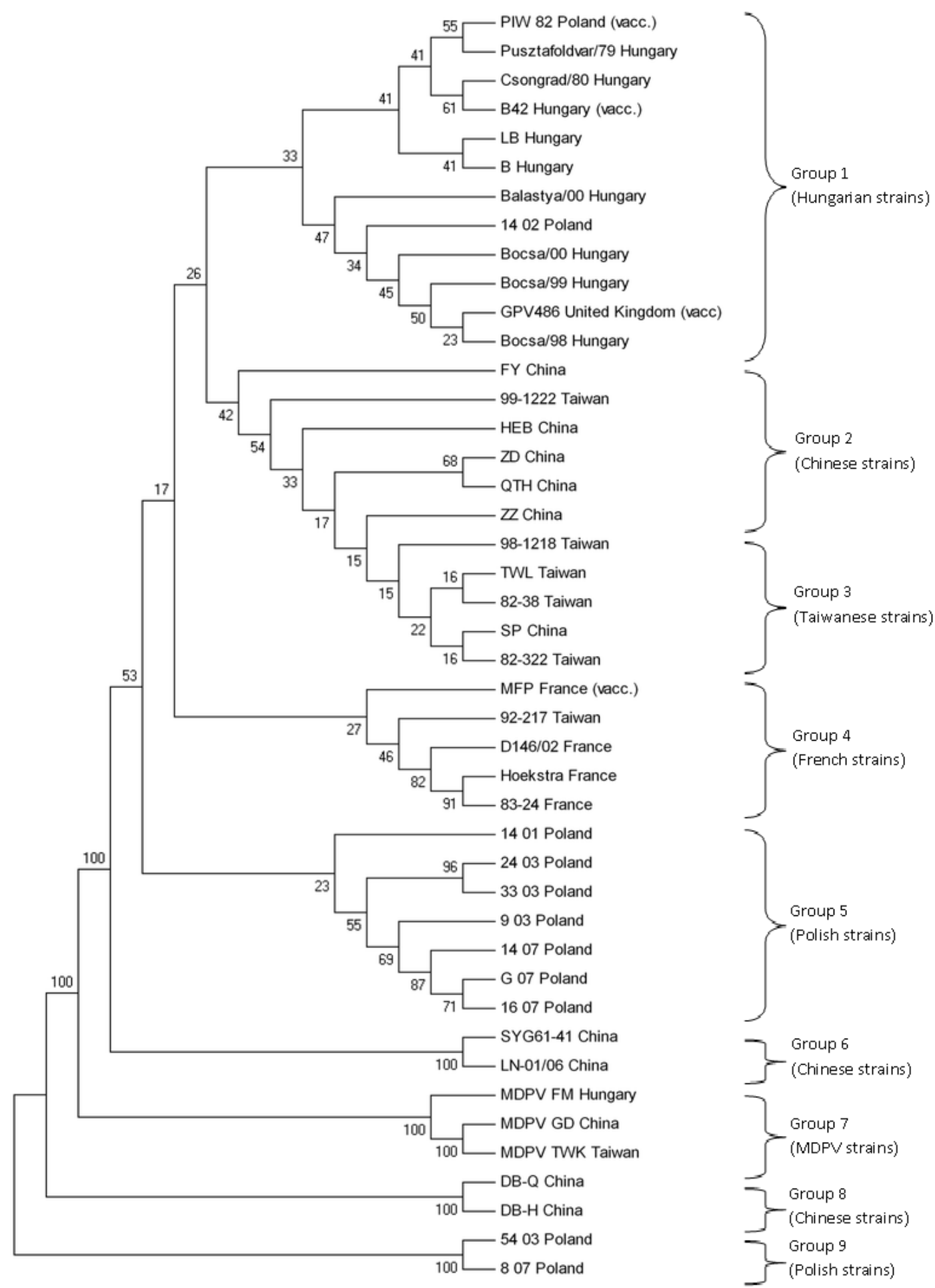

Figure 3. Phylogenetic tree of GPV and MDPV strains on the basis of VP3 encoding region (vacc = vaccine strain).

GPV and MDPV genomes (Zàdori et al, 1995; Tatar-Kis et al, 2004). Previously, Chang et al (2000) conducted the phylogenetic analysis of strains isolated in Taiwan using the $539 \mathrm{bp}$ fragment of the VP3 protein. Furthermore, the phylogenetic analysis of MDPV strains isolated in the USA (Pennsylvania) was done using sequences of six different genes (Poonia et al, 2006). In the present study, the phylogenetic analysis of GPV and MDPV was conducted on the basis of complete VP2 and VP3 encoding sequences. Previous work by Zadori et al (1995) suggests that the homology of the GPV and MDPV genomes was in the region of $81.9 \%$. Furthermore, Tsai et al (2004) observed that the common classification of MDPV strains was not dependent upon their geographical descent. The analysis of the VP3 encoding sequence of MDPV strains originating from China, Hungary and Taiwan revealed their close relationship. Moreover, higher homology of the MDPV sequences as compared to the 
Figure 4. Phylogenetic tree of the Polish strains of GPV and MDPV on the basis of VP3 amino acid sequence. The values on the axis multiplied by $100 \%$ give the identity coefficient of strains.

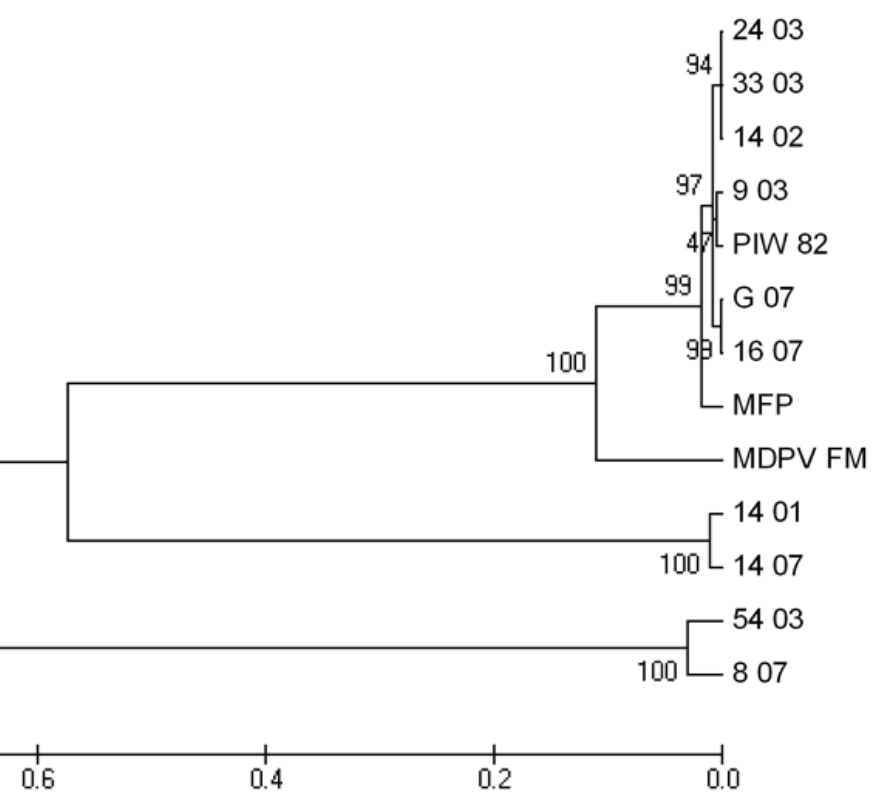

GPV sequences confirmed previous observations by Woolcock et al (2000). The nucleotide sequences of two major surface proteins of MDPV were less divergent as compared with the sequences of GPV strains. The comparison of the sequences of Polish strains with others isolated in Europe, China and Taiwan allowed for particular analysis of the Polish GPV strains. In the case of VP2 encoding sequence analysis, six different phylogenetic groups emerged, while for the VP3 encoding sequence nine phylogenetic groups were established. The nucleotide sequence of field strains isolated in Poland was similar to the vaccine strains used in the prophylactics of Derzsy's disease. Some of the Chinese strains fell into the phylogenetic group of strains isolated in the Taiwanese territory, while in the phylogenetic group of Taiwanese strains the strains isolated in China were found. Chang et al (2000) suggested Taiwan as an endemic area for this disease. Indeed, the conducted studies confirmed the low genetic variance at VP3 encoding sequence among these strains. Therefore, almost all Taiwanese strains were classified into a single group. However, in the 1990s, parallel outbreaks of Derzsy's disease were reported in France and Taiwan. It is probable that these outbreaks were caused by the same strain of goose parvovirus (Chang et al, 2000).

\section{CONCLUSIONS}

- Strains isolated in France and Hungary showed nucleotide sequence homology suggesting they share a common origin.

- GPV strains isolated during the period of 2002-2003 and 2007 formed common phylogenetic groups.

- Considerable diversity of the nucleotide and the predicted amino acid sequence was found in the case of a few Polish strains $(54 / 03,8 / 07,14 / 01,14 / 07)$, however, all Polish strains sequences were similar to Hungarian and French strains.

\section{ACKNOWLEDGEMENTS}

This research was funded by Polish Committee for Scientific Research, Grant G/004.

\section{COMPETING INTERESTS}

None declared.

\section{REFERENCES}

Chang PC, Shien JH, Wang MS, Shieh HK. 2000. Phylogenetic analysis of parvoviruses isolated In Taiwan from ducks and geese. Avian Pathol, 29, 45-49.

Chu CY, Pan MJ and Cheng JT. 2001. Genetic variation of the nucleocapsid genes of waterfowl parvovirus. J Vet Med Sci, 63, 1165-1170.

Cotmore SF and Tattersall P. 2006. Structure and organization of the viral genome. In Kerr JR, Cotmore SF, Bloom ME, Linden RM, Parrish CR (Eds). Parvoviruses. Oxford Univeristy Press, United Kingdom, 73-94.

Gough RE. 1998. Goose Parvovirus (Derzsy's Disease). In Swayne DE, Glisson JR, Jackwood MW, Pearson JE and Reed WM (eds). Isolation and Identification of Avian Pathogens. American Association of Avian Path. University of Pennsylvania, USA, 219-222.

Kozdruń W, Mato T, Palya V, Samorek-Salamonowicz E, Król K, Woźniakowski G. 2008. Phylogenetic analysis of Derzsy's disease virus isolated from geese in Poland. Medycyna Weterynaryjna, 64, 961-1072.

Le Gall-Recule G and Jestin V. 1994. Biochemical and genomic characterization of Muscovy duck parvovirus. Arch Virol, 139, 121-131.

Poonia B, Dunn PA, Lu H, Jarosinski KW, Schat KA. 2006. Isolation and molecular characterization of a new Muscovy duck parvovirus from Muscovy ducks in the USA. Avian Pathol, 35, 435-441.

Sirivan P, Obayashi M and Nakamura M. 1998. Detection of goose and Muscovy duck parvoviruses using polymerase chain reaction-restriction enzyme length polymorphism analysis. Avian Dis, 42, 133-139. 
Sneath PHA and Sokal RR. 1973. Numerical taxonomy. Woolcock PR, Jestin V, Shivaprasad F et al. 2000. Evidence of Freeman Publishing, USA

Tatár-Kis T, Mató T, Markos B, Palya V. 2004. Phylogenetic Muscovy duck parvovirus in Muscovy ducklings in California. analysis of Hungarian goose parvovirus isolates and vaccine strains. Avian Pathol, 33, 438-444.

Vet Rec, 146, 68-72.

Tsai HJ, Tseng CH, Chang PC, Mei K, Wang S. 2004 Genetic Variation of Viral Protein 1 Genes of Field Strains of Waterfowl Parvoviruses and Their Attenuated Derivatives. Avian Dis, 48, 512-521.

Zádori Z, Erdei J, Nagy J and Kisary J. 1994. Characteristics of the genome of goose parvovirus. Avian Pathol. 23, 359-364.

Zádori Z, Stefancsik R, Rauch T and Kisary J. 1995. Analysis of complete nucleotide sequences of goose and Muscovy duck parvoviruses indicates common ancestral origin with adenoassociated virus 2. Virology 212, 562-573. 